\title{
CONCESSÃO DE AEROPORTOS NO BRASIL: A TRANSFERÊNCIA DA GESTÃO DO AEROPORTO DE CONFINS PARA A INICIATIVA PRIVADA
}

\section{AIRPORT CONCESSION IN BRAZIL: THE TRANSFER OF CONFINS AIRPORT MANAGEMENT FOR PRIVATE ENTERPRISE}

\author{
Izabela Davanzo de Paiva \\ Universidade Federal de Alfenas UNIFAL-MG \\ izabeladavanzo@hotmail.com \\ Wesllay Carlos Ribeiro \\ Universidade Federal de Alfenas UNIFAL-MG \\ wesllay.ribeiro@gmail.com
}

Submissão: $29 / 09 / 2016$

Aprovação: 03/08/2017

\begin{abstract}
RESUMO
Esse artigo estuda o processo de transferência da gestão do Aeroporto Internacional Tancredo Neves- Confins do poder público para a iniciativa privada por meio da concessão. O edital do leilão e o contrato de concessão do Aeroporto de Confins foram os principais documentos estudados. Discute-se principalmente os pontos dessa concessão que destoam do regime de concessão previsto na legislação brasileira. Destaca-se que o alto valor de outorga no leilão é oposto à modicidade de tarifas, transformando a concessão em forma de o Estado arrecadar divisas e exigindo que o parceiro privado faça investimentos no setor aéreo como um todo. Outro ponto é a participação da Infraero, com $49 \%$ do capital social da concessionária, que cria um novo modelo de concessão, um híbrido que faz com que a União despenda e arrecade recursos de maneira concomitante. Com esse estudo pode-se concluir que a concessão do Aeroporto de Confins possui diversos aspectos controversos que deveriam ser profundamente discutidos pela academia e sociedade.
\end{abstract}

Palavras-Chave: Concessão de Aeroportos, Participação da Iniciativa Privada, Aeroporto de Confins, Concessão do Aeroporto de Confins, Aeroporto Internacional Tancredo Neves. 


\begin{abstract}
This paper studies the process of management transference of the Tancredo Neves International Airport- Confins from public ownership to the private sector through concession. The auction notice and the concession contract were the main documents studied. Mainly, it is discussed the aspects of this airport concession that differentiate from the concession model stipulated in the Brazilian legislation. It is emphasized that the high value of granting in the auction is opposite of fare moderateness, transforming the concession in a manner that the State raises money and requires the private partner to invest in the aviation business as a whole. Other point is the corporate participation of Infraero, with $49 \%$ of the capital stock of the concessionaire, that has created a new model of concession, a hybrid that makes the Brazilian government spend and raise its resources in a concomitant manner. With this study it can be concluded that the concession of Confins Airport has many controversial aspects that should be discussed deeply in the academy and the society.
\end{abstract}

Keywords: Airport Concession; Private Sector Participation; Confins Airport; Confins Airport Concession; Tancredo Neves International Airport. 


\section{INTRODUÇÃO}

O transporte aéreo é fundamental para um país com as dimensões do Brasil, possibilitando o deslocamento de pessoas e o transporte de cargas de diversos setores econômicos. Esse modal de transporte é um elemento de integração do território nacional e se constitui em um setor estratégico para o desenvolvimento do país (IPEA, 2010). Contudo, a infraestrutura aeroportuária brasileira possuía diversos problemas, tanto quantitativos como aeroportos saturados, atendendo além de sua capacidade anual (MCKINSEY \& COMPANY, 2010; CAMPOS NETO E SOUZA, 2011) como qualitativos com perdas de qualidade e eficiência do serviço (MARTINS E TESSEROLLI, 2013), entre outros.

A necessidade de enfrentamento dos problemas que assolavam a infraestrutura aeroportuária brasileira demandou mudanças por parte do setor público. Assim, foram escolhidos cinco aeroportos geridos pela Infraero, e mais um aeroporto a ser construído, que foram leiloados e concedidos teoricamente à iniciativa privada.

O modelo de concessão de aeroportos no Brasil é ainda incipiente. Seu início ocorreu com o leilão para a concessão do Aeroporto de São Gonçalo do Amarante, no Rio Grande do Norte, realizado em agosto de 2011. Houve ainda mais dois leilões de concessão de aeroportos geridos pela Infraero. Em fevereiro de 2012, o Aeroporto Internacional Governador André Franco Montoro em Guarulhos, o Aeroporto Internacional Juscelino Kubitschek em Brasília e o Aeroporto Internacional de Viracopos em Campinas; e em novembro de 2013, o Aeroporto Internacional Antônio Carlos Jobim- Galeão no Rio de Janeiro e o Aeroporto Internacional Tancredo Neves em Confins tiveram seus processos de concessão principiados, através dos leilões (ANAC, 2014).

Apesar de existirem estudos sobre o regime de concessão, especificamente a concessão dos aeroportos no Brasil é, até então, tema pouco estudado, inclusive pelo caráter inicial desses processos. Sendo assim, faz-se necessária uma pesquisa que analise as concessões, enfocando o setor aeroportuário brasileiro. Para tanto, optou-se por realizar uma análise do caso de um dos aeroportos concedidos pelo poder público para iniciativa privada: o Aeroporto Internacional Tancredo Neves, também conhecido como Aeroporto de Confins.

O referido aeroporto foi selecionado para esse estudo, primeiramente, por ter sido incluído há pouco tempo no Programa Nacional de Desestatização e seu Leilão de Concessão, ter ocorrido em novembro do ano de 2013. Desse modo, por serem eventos recentes, não foram encontradas na literatura pesquisas relacionadas ao tema.

Outra questão considerada foi a importância do aeroporto, reconhecida pelo Estudo de Viabilidade do Aeroporto Internacional Tancredo Neves, apresentado pela Agência Nacional de Aviação Civil- ANAC (2013b). No estudo são apresentadas algumas características do Aeroporto de Confins tais como: localização geográfica central; ser o principal aeroporto comercial na região de Belo Horizonte, maior cidade do estado de Minas Gerais e terceira maior região metropolitana do país; ser um hub (ponto de conexão) emergente para as companhias aéreas domésticas; possuir grande base de origem e destino (O\&D) de passageiros com um forte mercado de partidas; e em 2012 ter sido o quinto aeroporto em termos de serviço comercial no Brasil e o décimo primeiro de maior tráfego na América Latina. Assim, o Aeroporto de Confins se estabelece como um aeroporto de grande relevância para o tráfego aéreo brasileiro.

Destarte, pretende-se estudar o processo de transferência de gestão do Aeroporto de Confins para a iniciativa privada. Para que tal objetivo seja alcançado, faz-se necessário estudar os modelos nacionais e internacionais de participação da iniciativa privada na gestão de 
aeroportos e; descrever o processo de parceria entre o setor público e privado para a gestão do Aeroporto de Confins.

\section{MODELO JURÍDICO DE CONCESSÃO E A CONCESSÃO DOS AEROPORTOS NO BRASIL}

O art. 175 da Constituição da República Federativa do Brasil de 1988- CRFB/88 já previa os regimes de concessão e permissão de serviços públicos. Assim, em 1995 houve a edição da Lei $\mathrm{n}^{\circ}$ 8.987, que regulamenta a concessão e a permissão. A denominada Lei Geral das Concessões propicia que esses regimes venham auxiliar nos processos de desestatização, conforme disposto no Programa Nacional de Desestatização - PND, reformulado em 1997 por meio da Lei 9.49 (BRASIL, 1997).

Como a operação e a exploração de aeroportos no Brasil são consideradas serviços públicos, já está previsto na constituição que podem ser realizadas por meio de concessão ou permissão. Embora os dois regimes estejam dispostos na CRFB/88, apenas a concessão está elencada como possibilidade para a gestão de aeroportos no Código Brasileiro de Aeronáutica de 1986$\mathrm{CBA} / 86$. A autorização, forma de gestão também citada no $\mathrm{CBA} / 86$, possui diversas peculiaridades que inviabilizam sua utilização em aeroportos de propriedade pública e com voos regulares.

Dessarte, o governo brasileiro optou por utilizar a concessão para disciplinar a participação da iniciativa privada em grandes aeroportos já existentes.

Tratando mais sobre o regime de concessão, Bandeira de Mello (2010) traz uma definição próxima à lei, apontando que a concessão é o instituto em que um serviço público é delegado pelo Estado à iniciativa privada, por sua livre vontade, através de um contrato. A garantia contratual garante um equilíbrio econômico-financeiro e a remuneração da empresa privada ocorre, principalmente, por tarifas cobradas diretamente dos usuários.

Para Justen Filho (2011, p.713), "a concessão de serviço público é um instrumento de implementação de políticas públicas". Essa se constitui na união de esforços entre o poder público e a iniciativa privada, objetivando a maior eficácia na aplicação dos recursos econômicos e melhor qualidade e eficiência aos serviços públicos, sendo a mais conhecida forma de delegação de serviço público (JUSTEN FILHO, 2011). O autor coloca a concessão não apenas como modelo jurídico, mas também como ferramenta que auxilia na gestão de serviços públicos.

É importante ressaltar que embora seja caracterizada como desestatização, a concessão não constitui uma forma de privatização, já que é sempre instituída por meio de contrato em que a titularidade do serviço permanece com o poder público, transferindo-se apenas sua execução para a iniciativa privada (DI PIETRO, 2011).

Para dispor sobre a concessão, como forma de participação da iniciativa privada na exploração da infraestrutura aeroportuária, foi instituído o Decreto $\mathrm{n}^{\mathrm{o}} 7.624$, de 22 de novembro de 2011. Este decreto trata, de maneira geral, sobre as condições de exploração, e de como serão configurados o edital e o contrato de concessão. Entende-se, que a legislação sobre a exploração dos aeroportos pela iniciativa privada já existia na CRFB/88 e no CBA/86, e este decreto veio apenas disciplinar alguns pontos práticos do processo de concessão.

O modelo adotado pelo governo brasileiro para a concessão dos aeroportos é, pela legislação do país, caracterizada como concessão tradicional de serviço público e de obra pública. Conforme Di Pietro (2011), o instituto da concessão pode envolver, além do serviço público, 
obra pública. Nesse caso, ele é denominado concessão de serviço público precedido de obra pública e está disposto no art. $2^{\circ}$, III da Lei 8.987/95 como:

a construção, total ou parcial, conservação, reforma, ampliação ou melhoramento de quaisquer obras de interesse público, delegadas pelo poder concedente, mediante licitação, na modalidade de concorrência, à pessoa jurídica ou consórcio de empresas que demonstre capacidade para a sua realização, por sua conta e risco, de forma que o investimento da concessionária seja remunerado e amortizado mediante a exploração do serviço ou da obra por prazo determinado. (BRASIL, 1995)

Compreende-se, assim, que nessa modalidade, a obra, quer seja construção, reforma ou conservação, é necessária para a execução do serviço concedido, e dessa forma, ao executá-la, o concessionário recebe por ambos como é o caso da concessão dos aeroportos brasileiros.

Assim a concessão teve seu início nos aeroportos geridos pela Infraero em 2011, com o leilão de concessão para a construção parcial, manutenção e exploração do Aeroporto Internacional de São Gonçalo do Amarante no Rio Grande do Norte. O valor da outorga foi de R\$ 650 milhões. A concessão tem prazo de 28 anos e a concessionária é a Inframerica. Na concessão do Aeroporto de São Gonçalo do Amarante a Infraero não consta como acionista (ANAC, 2014). A concessão teve início em janeiro de 2012 e o aeroporto foi entregue em maio de 2014 (SAC/PR, 2014).

Os Aeroportos de Guarulhos, Viracopos e Brasília foram leiloados em um mesmo processo, que ocorreu em fevereiro de 2012 na Bolsa de Valores de São Paulo (INFRAERO, 2014).

O Aeroporto de Guarulhos teve a concessão dos serviços públicos para a ampliação, manutenção e exploração da infraestrutura de seu complexo aeroportuário pelo prazo de 20 anos. O lance vencedor foi o do Consórcio Invepar - formado pela Invepar (Investimentos e Participações em Infraestrutura S.A) e ACSA, da África do Sul no valor de R\$ 16,213 bilhões (INFRAERO, 2014). Essas empresas juntamente com a Infraero constituíram a GRU Airport, concessionária responsável pelo Aeroporto de Guarulhos (ANAC, 2014).

Segundo a Infraero (2014), o Aeroporto de Viracopos foi concedido ao Consórcio Aeroportos Brasil, constituído pela Triunfo Participações e Investimentos , UTC Participações e Egis Airport Operation pelos valor de R \$ 3,821 bilhões. Esse consórcio em parceria com a Infraero compõe a Aeroportos Brasil Viracopos, concessionária que pelo prazo de 30 anos deverá ampliar, manter e explorar o complexo aeroportuário (ANAC, 2014).

O terceiro aeroporto concedido no mesmo leilão foi o Aeroporto de Brasília que foi arrematado por $\mathrm{R} \$ 4,501$ bilhões pelo consórcio que reúne as empresas Infravix Participações SA e Corporacion America SA (INFRAERO, 2014). De acordo com a ANAC (2014), o prazo da concessão é de 25 anos. E a concessionária formada em parceria com a Infraero é a INFRAMÉRICA, mesma concessionária do Aeroporto de São Gonçalo do Amarante, contudo, naquele aeroporto não há participação da estatal.

Outro lote de aeroportos, Aeroporto do Galeão e o de Confins, foi leiloado em novembro de 2013. Conforme exposto pela Infraero (2014), o Aeroporto Internacional Antônio Carlos Jobim - Galeão foi arrematado com ágio de $293 \%$, pelo valor R 19 bilhões, pelo Consórcio Aeroportos do Futuro, constituído por Odebrecht Transport, e a Operadora do Aeroporto de Cingapura CHANGI. A concessionária com participação da Infraero é denominada Aeroporto Rio de Janeiro S.A. e terá a concessão pelo prazo de 25 anos.

A concessão do Aeroporto de Confins será apresentada na próxima seção, pois esse é o principal objeto de estudo do presente trabalho.

De acordo com a Infraero (2015b) os seis aeroportos juntos respondiam em 2012 por $44 \%$ dos passageiros, $28 \%$ das Aeronaves e $62 \%$ da carga aérea da Rede de Aeroportos da Infraero, e eram responsáveis, nesse mesmo ano, por $53 \%$ do faturamento da Rede. Entende-se, dessarte, que o modelo de concessão foi instaurado predominantemente nos principais aeroportos, 
localizados nos grandes centros, que geravam mais da metade do faturamento da Rede Infraero.

Um ponto peculiar das concessões, exceto o Aeroporto Internacional de São Gonçalo do Amarante, é possuírem a Infraero como acionista, com $49 \%$ do capital social de cada concessionária. Segundo a própria Infraero a empresa "participa da governança dos aeroportos na proporção de sua participação acionária nas concessionárias, com poder de decisão em temas relevantes, que foram estabelecidos em acordos de acionistas firmados entre as partes" (INFRAERO, 2014). Dessa forma, a empresa pública, que já administrava os aeroportos, se mantém na gestão dos mesmos, detendo $49 \%$ das ações de cada concessionária. Essa questão será discutida na seção que trata sobre a concessão do Aeroporto de Confins.

\section{PERCURSO METODOLÓGICO}

O presente trabalho utiliza a abordagem qualitativa, tendo como objeto de estudo o processo de transferência de gestão do Aeroporto de Confins para a iniciativa privada. A técnica de pesquisa utilizada foi a pesquisa documental e os documentos que compõem o corpus do trabalho são: Edital n⿳亠丷厂 $1 / 2013$ e anexos; Contrato e anexos; Lei n ${ }^{\circ}$ 8.987/1995; Acórdão 2466/2013- TCU; Acórdão 2666/2013 - TCU; Acórdão 2945/2014- TCU; Relatório da administração 2014- Infraero

A técnica de análise dos dados utilizada foi uma livre adaptação da análise de conteúdo. Segundo Bardin (1977), a análise de conteúdo abarca iniciativas que se baseiem na explicitação, sistematização e expressão do conteúdo das mensagens, com a finalidade de elaborar deduções lógicas e justificadas. Assim as etapas seguidas foram explicitação, sistematização e expressão do conteúdo dos documentos que fazem parte do corpus desse trabalho, e ao final foram formuladas inferências embasadas nesse processo.

\section{A CONCESSÃO DO AEROPORTO DE CONFINS}

Devido à sua grande relevância para o tráfego aéreo nacional, cumprindo papel importante no transporte aéreo regional, nacional e internacional (ANAC, 2013b), à crescente demanda de passageiros e cargas, e à necessidade de investimentos (SAC/PR, 2014), o Aeroporto de Confins foi escolhido pelo governo federal para ser concedido à iniciativa privada por meio de leilão.

Os estudos sobre a concessão do Aeroporto de Confins foram focados principalmente no edital, no leilão e no contrato. Contudo, o processo não foi iniciado com a publicação do edital. A linha do tempo, representada na figura 1, mostra as etapas que envolveram o processo de concessão até a assinatura do contrato e quando ocorreram.

Figura 1- Linha do tempo concessão do Aeroporto de Confins. 


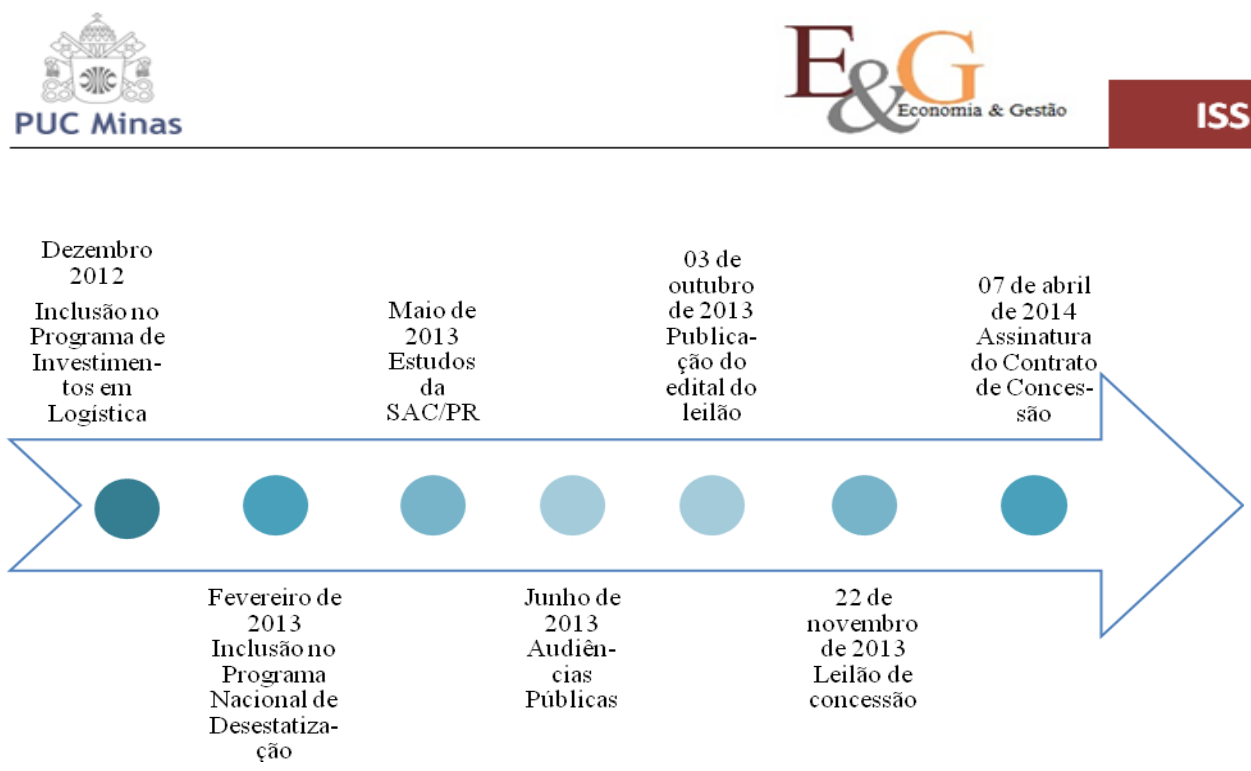

Fonte: SAC/PR (2014). Elaboração própria.

\subsection{O edital e o processo de licitação}

O Decreto $n^{\circ} 7.624 / 2011$ dispõe que o processo de licitação dos aeroportos poderá ser realizado nas modalidades de concorrência ou leilão. A modalidade de leilão foi a escolhida para a concessão do Aeroporto de Confins.

Já na seção I do capítulo I do Edital do Leilão 01/2013, elaborado pela ANAC (2013c), são apresentadas as definições das expressões utilizadas no documento. Evidencia-se para a conceituação de concessão: "concessão de serviços públicos de que trata a Lei Federal no 8.987/95, de 13 de fevereiro de 1995, cujo escopo é a ampliação, manutenção e exploração do Aeroporto objeto do Contrato" (ANAC, 2013c). Dessarte, constata-se que a concessão do Aeroporto de Confins é uma concessão de serviço público e obra pública, regida pela lei $\mathrm{n}^{\circ}$ 8.987.

O objeto do leilão, pelo título do edital é estabelecido como a Concessão para Ampliação, Manutenção e Exploração dos Aeroportos Internacionais Rio de Janeiro/Galeão - Tancredo Neves/Confins. Ainda que o objeto pareça ser a concessão dos dois aeroportos de forma conjunta, há, de fato, dois objetos, sendo a concessão do Aeroporto do Galeão um propósito, e a concessão do Aeroporto de Confins outro. Cada aeroporto foi leiloado separadamente, contudo o critério de julgamento dos vencedores foi o maior Valor Global de Contribuição Fixa $^{1}$ (ANAC, 2013c).

Todavia, como apresentado no item 1.5 do edital cada proponente poderia adjudicar apenas um único aeroporto (ANAC, 2013c). Desse modo, cada participante, denominado no edital como proponente, poderia ofertar lances para os dois aeroportos, entretanto só seria reconhecido como titular de uma concessão (BELÉM, 2013).

Os documentos exigidos das proponentes, segundo o edital (ANAC, 2013c), foram divididos em três volumes. No primeiro volume as proponentes deveriam apresentar as Declarações Preliminares; os Documentos de Representação; e Garantia de Proposta, em que as proponentes interessadas deveriam aportar garantias no valor mínimo de $\mathrm{R} \$$ 51.169.860,00 para o Aeroporto de Confins. No segundo volume era necessário constar a Proposta Econômica. E o terceiro volume deveria ser composto pelos Documentos de Habilitação.

\footnotetext{
${ }^{1}$ O edital dispõe que Valor Global de Contribuição Fixa consiste no somatório do Valor de Contribuição Fixa da Proponente Titular de cada Aeroporto, observadas as regras da Sessão Pública de Leilão (ANAC, 2013c).
} 
A Proposta Econômica consistiu no lance inicial do Valor de Contribuição Fixa pela concessão, que no caso do Aeroporto de Confins era de no mínimo R \$1.096.372.000,00. Essa proposta deveria ser incondicional, irretratável e irrevogável, assim como os lances do leilão na etapa de viva-voz (ANAC, 2013c).

Os Documentos de Habilitação foram divididos em quatro subcategorias: habilitação jurídica; habilitação econômico-financeira; regularidade fiscal e trabalhista e; habilitação técnica. Quanto ao último ponto destaca-se que:

é requisito de qualificação técnica para apresentação de propostas que o Operador Aeroportuário possua experiência mínima de 5 (cinco) anos na operação de um mesmo aeroporto que tenha processado, no mínimo: (i) Para o aeroporto de Confins: 12 (doze) milhões de passageiros em pelo menos 1 (um) ano civil, nos últimos 5 (cinco) anos anteriores ao da publicação deste Edital, considerado o somatório de passageiros embarcados, desembarcados e em trânsito de experiência do operador aeroportuário, de no mínimo cinco anos, na administração de um aeroporto que tenha movimentado 12 milhões de passageiros em pelo menos um ano dos últimos cinco (ANAC, 2013c).

Esse requisito demonstra a preocupação em escolher um operador que traga sua experiência internacional em administrar aeroportos do porte de Confins. A Secretaria de Aviação Civil (2014) afirma que esse modelo proporcionará a troca de experiências e a absorção das melhores práticas existentes no setor aéreo.

Mais um aspecto que merece destaque, tratando-se do leilão, diz respeito às suas etapas, em que houve a inversão de fases. Antes da sessão pública do leilão houve a apresentação dos documentos da proponente e a análise apenas das Declarações Preliminares, Documentos de Representação e Garantia de Proposta, ou seja do volume um. Somente após a sessão pública que os Documentos de Habilitação da proponente classificada em primeiro lugar foram analisados e julgados (ANAC, 2013).

Justen Filho (2011) pondera que a inversão de fases no leilão restringe o nível de segurança da administração pública, já que há uma tendência em transpor deficiências na habilitação devido à suposta vantagem da proposta financeira, e que somente licitações de pequenos valores deveriam utilizar essa inversão de fases.

A questão elucidada pelo autor não pôde ser averiguada na presente pesquisa, todavia seu apontamento demonstra que para o leilão dos aeroportos, que possuem alto valor, seria desaconselhável inverter as fases dessa maneira.

O julgamento da licitação seguiu o critério definido pela Lei $n^{\circ} 8.987 / 75$ art. 15 II, incluído pela Lei $\mathrm{n}^{\circ}$ 9.648, de 1998, isto é, a maior oferta de pagamento ao poder concedente pela outorga da concessão. A outorga por leilão é compatível a esse critério de julgamento. Contudo, a escolha desse critério não é ponto pacífico e será abordada na seção que trata sobre o contrato.

Nessas circunstâncias, o Leilão $n^{\circ}$ 01/2003 teve sua sessão pública no dia 22 de novembro de 2013 na BM\&FBovespa. A primeira etapa da sessão foi a abertura das propostas que eram oito, de cinco diferentes consórcios. Em seguida houve a classificação das proponentes, em que três consórcios foram classificados para cada aeroporto. Logo após foi realizado o leilão em viva-voz, simultâneo para os dois aeroportos, todavia, nessa etapa, só houve lances para o Aeroporto de Confins (BM\&FBOVESPA, 2014). Segundo a BM\&FBovespa (2013), o grupo vencedor do leilão do Aeroporto de Confins é denominado Consórcio Aerobrasil, e é constituído pelas empresas Companhia de Participações em Concessões-CPC, Zurich Airport Internacional $A G$ e Munich Airport Internacional Beteiligungs-GMBH. O lance vencedor foi de $\mathrm{R} \$ 1,82$ bilhão, $66 \%$ a mais do que o valor mínimo proposto no edital, representando o valor da contribuição fixa que a concessionária terá que pagar durante o prazo de vigência do contrato. 
O operador aeroportuário com experiência em gestão de aeroporto com fluxo mínimo de 12 milhões de passageiros anuais, exigido no edital é a empresa Zurich Airport Internacional $A G$. Tanto no contrato, como nos documentos posteriores não há menção à Munich Airport Internacional Beteiligungs-GMBH. A ANAC (2015) indicou que a saída da empresa ocorreu devido a uma reorganização societária, nos termos previstos no Contrato de Concessão.

Espírito Santo Jr., Prazeres e Santana (2010) afirmam que um dos pontos cruciais para o bom andamento da concessão de aeroportos é o edital. Este deve considerar especialmente três áreas: a sociedade, a economia e o setor aéreo. Para os autores, se a concessão for planejada em prol dessas três áreas, iniciando no edital do leilão, essa terá maiores possibilidades de atingir seu potencial benéfico.

Acredita-se que o edital foi elaborado com grande enfoque na economia e no setor aéreo, ficando a sociedade com um papel secundário. Contudo, o documento como um todo prima a qualidade do serviço prestado, melhorias nos aeroportos e consequentemente no setor aéreo, e todos esses pontos favorecem a sociedade direta e indiretamente.

\section{$4.2 \mathrm{O}$ contrato de concessão}

O objeto do contrato é a concessão de serviços públicos para a ampliação, manutenção e exploração da infraestrutura do Complexo Aeroportuário de Confins. O prazo dessa concessão é de 30 anos, com a possibilidade de prorrogação por até cinco anos, uma única vez, para a recomposição do equilíbrio econômico-financeiro da concessionária, em decorrência de revisão extraordinária como prevista no contrato (ANAC, 2014).

As atividades que deverão ser desempenhadas pela concessionária, durante todo o prazo de vigência da concessão, consistem: a) na prestação de serviços de embarque, desembarque, pouso, permanência, armazenagem, capatazia e todos os serviços relacionados à infraestrutura aeroportuária; b) na exploração eficiente do complexo aeroportuário a fim de obter receitar não-tarifárias, e disponibilizar aos usuários a infraestrutura de apoio necessária ao bom funcionamento; c) na manutenção de todas as instalações, bens e equipamentos já existentes ou implementados; d) na execução de melhorias da infraestrutura para ampliar o complexo aeroportuário e adequar a qualidade dos serviços; e) no atendimento pleno ao nível de serviço previsto no Plano de Exploração Aeroportuária (PEA) mediante a realização dos investimentos e obtenção dos recursos necessários; f) e na adequação das outras instalações relevantes ao atendimento dos usuários, na hipótese de ampliação do complexo aeroportuário, em especial pátio de aeronaves, estacionamento de veículos, vias de acesso, entre outras (ANAC, 2014).

É importante ressaltar que a prestação dos serviços destinados a apoiar e garantir segurança à navegação aérea em área de tráfego aéreo do Aeroporto não é objeto dessa concessão, sendo atribuição exclusiva do poder público (ANAC, 2014).

Constata-se dessa maneira, que a concessão abrange apenas instalações, serviços e facilidades não-aeronáuticas (lado terra) e algumas atividades aeronáuticas de manuseio. A execução das atividades aeronáuticas operacionais não foi transferida à concessionária, permanecendo com o poder público, já que é competência restrita do mesmo.

O contrato foi firmado entre a ANAC, representando o poder concedente, e a Concessionária do Aeroporto Internacional de Confins S.A. com interveniência da Sociedade de Participação no Aeroporto de Confins S.A. e da Infraero (INFRAERO, 2014). A concessionária é denominada $B H$ Airport, e sua composição está representada na figura abaixo.

Figura 2- Composição acionária da Concessionária BH Airport. 


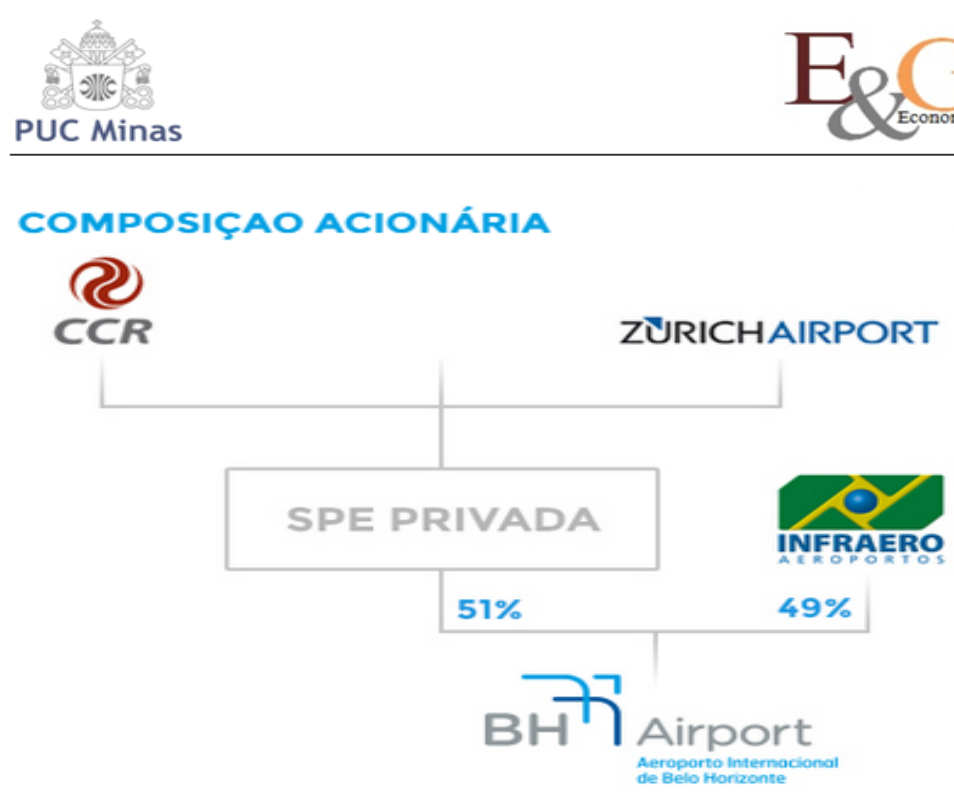

Fonte: BH AIRPORT (2014).

O grupo CCR é uma fusão de três grandes grupos brasileiros: Soares Penido, Andrade Gutierrez e Camargo Correa, mais ações negociadas no Novo Mercado da BM\&FBOVESPA. Ainda que possua alguma experiência em concessão de aeroportos, o Grupo CCR não atenderia ao requisito da qualificação técnica de experiência mínima de 5 anos na operação de um aeroporto do porte de Confins.

Assim, para atender ao requisito de experiência, a Sociedade de Propósito Específico$\mathrm{SPE}^{2}$ possui a participação da Zurich Airport, empresa privada cotada na bolsa de valores (ZURICH AIRPORT, 2014) que desde 2000 opera o Aeroporto de Zurique na Suíça, além de possuir participação em aeroportos em mais seis países (ZURICH AIRPORT, 2014). O principal fator que a qualifica para atender ao requisito de experiência, disposto no edital de concessão, é operar o Aeroporto de Zurique, que em 2012 movimentou 24.802.400 passageiros (ZURICH AIRPORT, 2014).

Assim, a SPE privada que compõe a concessionária do Aeroporto de Confins formada pela CCR e pela Zurich Airport possui 51\% das ações da concessionária e conforme exposto na figura 1, a Infraero é a acionista que detém os outros $49 \%$ do capital social da concessionária. Esse modelo de participação da Infraero ocorre nos cinco principais aeroportos concedidos, excetuando-se apenas o Aeroporto de São Gonçalo do Amarante/RN. A empresa participa da governança de cada um dos aeroportos, possuindo poder de decisão, estabelecido em acordos de acionistas. Todavia, não possui o controle dos aeroportos (INFRAERO, 2015). Além da governança, a empresa também aporta capital nas SPEs correspondendo aos $49 \%$ do capital social que possui (INFRAERO, 2015B).

Nos Acórdãos 3232/2011, 3233/2011 e 3234/2011 - TCU Plenário afirma-se que uma das principais justificativas da implantação da concessão está na eficiência, qualidade, práticas e incentivos ao mercado, proporcionados pela administração privada. Assim, a participação da Infraero poderia acarretar prejuízos à capacidade decisória da concessionária, já que a esfera pública e a iniciativa privada são conduzidas por lógicas distintas, trazendo riscos à governança corporativa da SPE (TCU, 2011).

Outro ponto destacado nesses documentos é a necessidade de incorporação da Infraero apresentada pela ANAC e SAC/PR para garantir o repasse dos recursos recebidos pelos aeroportos concedidos aos demais aeroportos brasileiros (TCU, 2011). As entidades estatais -

\footnotetext{
2 Sociedade de Propósito Específico- SPE refere-se à empresa criada pelo consórcio dedicada somente à prestação do serviço público. Seu capital e negócio são dissociados das empresas que deram origem ao consórcio (GROTTI, 2011).
}

E\&G Economia e Gestão, Belo Horizonte, v. 17, n. 47, Maio/Ago. 2017 
ANAC e SAC/PR estão assim, afirmando que a participação da Infraero nas concessionárias dos aeroportos é crucial para que se mantenham os subsídios cruzados reconhecidos por muitos autores como uma grave deficiência dessa empresa. O próprio TCU desaprova essa justificativa ao salientar que:

Não subsiste, entretanto, o alegado nexo essencial entre a incontroversa necessidade de se financiar os demais aeródromos públicos - em sua maioria deficitários (seja por ineficiência da gestão pública ou por estratégia de desenvolvimento regional e integração nacional) - e a participação da atual operadora na futura incumbente. Pondera-se que é possível conceber inúmeras formas alternativas para custear a manutenção e a ampliação da malha aérea nacional - mesmo a partir das receitas geradas no aeroporto em epígrafe -, sendo que várias dessas maneiras resultam menos distorcivas do que a operação do serviço por uma SPE composta por expressiva participação de entidade pública (TCU, 2011, p.20).

Dessarte, o TCU (2011) recomendou à Casa Civil da Presidência da República, à SAC/PR e à ANAC que fosse reconsiderada a obrigatoriedade de participação da Infraero na futura SPE ou, ainda, que fosse estabelecida, cláusula prevendo a diminuição da empresa na participação no capital social da SPE. No Acórdão 2466/2013 TCU-Plenário relacionado à concessão dos Aeroportos de Confins e Galeão, o TCU apontou que essa recomendação não foi implementada.

O mesmo tribunal (TCU, 2013a) afirma que a atuação da agência reguladora- ANAC possibilitaria resultados mais voltados ao interesse público do que a participação direta da Infraero na SPE e que a permanência da empresa estatal é injustificada, constituindo-se em um risco dispensável à concessão.

Martins e Tesserolli (2013) apontam que a participação da Infraero nas SPEs traz grande preocupação, e deve ser revista. Eles ainda sinalizam que não há justificativa razoável para essa participação. Especialmente, se os resultados recebidos pela Infraero, como sócia das SPEs, forem repassados ao sistema de distribuição de divisas que favorece o Tesouro Nacional e o Comando da Aeronáutica, sem destinação exclusiva à infraestrutura aeroportuária. (MARTINS E TESSEROLLI, 2013).

Até o próprio significado da concessão parece desfigurado. Segundo Grotti (2011), nesse instituto o Estado confere a um ente o exercício de um serviço público, e este o executa em nome próprio, por sua conta e risco. No caso da concessão de aeroportos o ente privado não opera os aeroportos em nome próprio, por sua conta e risco, ele divide sua participação com a empresa estatal, que possui $49 \%$ das ações da concessionária. Dessa forma, parece não haver autonomia para que a iniciativa privada desempenhe suas atribuições.

Justen Filho (2011, p.721) pondera que "somente se configura a concessão quando houver a delegação dos serviços públicos para a iniciativa privada. A atribuição da prestação do serviço para uma entidade estatal descaracteriza uma concessão." Contudo, a concessão dos aeroportos no Brasil é composta tanto da delegação dos serviços para a iniciativa privada, quanto para uma entidade estatal. Possui assim, aspectos que se configuram como concessão e a participação da Infraero que deturpa o regime de concessão previsto da legislação brasileira. Pode-se afirmar que a participação acionária da Infraero não é um ponto do contrato desprovido de questionamentos e preocupações, trazendo interpretações diversas ao significado do instituto da concessão e podendo ocasionar prejuízos à mesma concessão dos aeroportos.

Quanto à remuneração da concessionária há questões relacionadas aos tipos de receitas e ao valor das tarifas. A concessionária do Aeroporto de Confins receberá retorno financeiro pelos serviços prestados de duas formas: pelas receitas tarifárias e pelas receitas não tarifárias.

Antes de tratar sobre as formas de remuneração, cabe ressaltar que como acionista da SPE que administra o Aeroporto de Confins, a Infraero receberá os ganhos financeiros da concessionária proporcionalmente à sua participação acionária de $49 \%$. 
As receitas tarifárias, nesse caso, são oriundas das tarifas aeroportuárias dispostas na Lei $\mathrm{n}^{\mathbf{o}}$ 6.009/73 e são apresentadas no Quadro 2.

Quadro 2- Tarifas Aeroportuárias

\begin{tabular}{|c|c|c|}
\hline Tarifa & Motivo & $\begin{array}{l}\text { Responsável pela } \\
\text { remuneração }\end{array}$ \\
\hline $\begin{array}{c}\text { Tarifa de } \\
\text { embarque }\end{array}$ & $\begin{array}{l}\text { Utilização das instalações e serviços } \\
\text { de despacho e embarque da Estação de } \\
\text { Passageiros }\end{array}$ & Passageiro do transporte aéreo \\
\hline Tarifa de pouso & $\begin{array}{l}\text { Utilização das áreas e serviços } \\
\text { relacionados com as operações de } \\
\text { pouso, rolagem e estacionamento da } \\
\text { aeronave até três horas após o pouso }\end{array}$ & $\begin{array}{l}\text { Proprietário ou explorador da } \\
\text { aeronave }\end{array}$ \\
\hline $\begin{array}{c}\text { Tarifa de } \\
\text { permanência }\end{array}$ & $\begin{array}{l}\text { Estacionamento da aeronave, além das } \\
\text { três primeiras horas após o pouso }\end{array}$ & $\begin{array}{l}\text { Proprietário ou explorador da } \\
\text { aeronave }\end{array}$ \\
\hline $\begin{array}{c}\text { Tarifa de } \\
\text { Armazenagem }\end{array}$ & $\begin{array}{l}\text { Armazenamento, guarda e controle das } \\
\text { mercadorias nos Armazéns de Carga } \\
\text { Aérea dos Aeroportos }\end{array}$ & $\begin{array}{l}\text { Consignatário ou transportador } \\
\text { no caso de carga aérea em } \\
\text { trânsito }\end{array}$ \\
\hline $\begin{array}{l}\text { Tarifa de } \\
\text { Capatazia }\end{array}$ & $\begin{array}{l}\text { Movimentação e manuseio das } \\
\text { mercadorias nos Armazéns de Carga } \\
\text { Aérea dos Aeroportos }\end{array}$ & $\begin{array}{l}\text { Consignatário ou transportador } \\
\text { no caso de carga aérea em } \\
\text { trânsito }\end{array}$ \\
\hline $\begin{array}{l}\text { Tarifa de } \\
\text { Conexão }\end{array}$ & $\begin{array}{l}\text { Alocação de passageiro em conexão } \\
\text { em Estação de Passageiros durante a } \\
\text { execução do contrato de transporte }\end{array}$ & $\begin{array}{l}\text { Proprietário ou explorador da } \\
\text { aeronave }\end{array}$ \\
\hline
\end{tabular}

Fonte: BRASIL (1973). Elaboração Própria.

Esse quadro apresenta as denominações das tarifas, as circunstâncias em que são cobradas e quem são os entes responsáveis pelos pagamentos de cada uma. Ressalta-se que exceto as tarifas de armazenagem e de capatazia, que se referem a cargas, as demais tarifas são custeadas pelos usuários dos aeroportos de maneira direta (tarifa de embarque) ou de maneira indireta (tarifa de pouso, tarifa de decolagem, tarifa de permanência e tarifa de conexão).

Quando as tarifas são custeadas de maneira indireta, as companhias áreas são responsáveis pelos pagamentos, contudo acrescentam esses custos aos valores de suas passagens. Com isso, há a possibilidade de ônus para os usuários que irão arcar com esses valores, o que é oposto ao princípio da modicidade de tarifas. Contudo, o TCU (2014) afirma que a modicidade de tarifas está presente nesse processo de concessão, primeiramente na fixação inicial das tarifas aeroportuárias, que seguiram os parâmetros utilizados pela Infraero; e também na hipótese de recomposição do equilíbrio econômico-financeiro, ocorrendo ganhos econômicos de novas fontes geradoras de receitas tarifárias. Todas as tarifas, independente do responsável pela remuneração, têm seu teto fixado no contrato.

As receitas não tarifárias são provenientes da exploração de atividades econômicas de forma direta ou por meio de contrato com terceiros em regime de direito privado. Segundo a Infraero (2014) são resultantes da utilização de áreas, edifícios, instalações, equipamentos, facilidades e serviços, que não são contempladas pelas tarifas aeroportuárias.

De acordo com o TCU (2013) as receitas não-tarifárias de maior importância são divididas em: lojas francas (duty free shops); aluguéis de áreas comerciais; estacionamento; taxas de combustível; publicidade; e alimentos e bebidas. A concessionária receberá assim, pela exploração direta ou locação dos espaços e atividades acima mencionadas. Não há, no contrato, menção de necessidade de licitação para contratação dos terceiros que exploram as 
atividades econômicas acessórias, diferindo da gestão Infraero que tem essas atividades reguladas pela Lei $\mathrm{n}^{\circ}$ 8.666/93. Segundo o TCU, (2014) no setor aeroportuário, essas receitas são fundamentais para garantir a viabilidade do empreendimento.

As receitas não tarifárias obtidas pelo concessionário podem ter reflexo no valor das tarifas pagas direta ou indiretamente pelos usuários, auxiliando no princípio da modicidade de tarifas.

O Acórdão 3.232/2011- TCU- Plenário recomendou à ANAC que fosse incluído no contrato de concessão um dispositivo que pudesse garantir a reversão de receitas não tarifárias a favor da modicidade das tarifas e/ou dos preços específicos praticados no próprio aeroporto, durante a execução contratual. Contudo, conforme apresentado pelo Acórdão 2945/2014- TCUPlenário essa recomendação não foi implementada. Desse modo, ainda que as receitas não tarifárias da concessionária possam ser utilizadas para manter a modicidade de tarifas, essa situação não está prevista pelo contrato de concessão.

O princípio da modicidade de tarifas sofre também a influência das obrigações financeiras da concessionária. Conforme disposto no contrato, a concessionária deve pagar anualmente ao poder concedente (União) a contribuição fixa e a contribuição variável, mediante depósito no Fundo Nacional de Aviação- FNAC.

O valor mínimo, previsto no edital, da contribuição fixa a ser paga ao poder concedente pelo Aeroporto de Confins era de $\mathrm{R} \$ 1$ 1.096.372.000,00. Contudo, a oferta do leilão do grupo vencedor foi $66 \%$ superior. Dessa maneira, a contribuição fixa que deverá ser paga pela concessionária é de $\mathrm{R} \$ 1,82$ bilhão e conforme exposto no contrato:

2.14 A Contribuição Fixa corresponde ao montante anual de R \$60.666.666,66 (sessenta milhões, seiscentos e sessenta e seis mil, seiscentos e sessenta e seis reais e sessenta e seis centavos), decorrente da oferta realizada no Leilão objeto da presente Concessão.

2.14.1 O montante anual da Contribuição Fixa corresponde à divisão do valor da Contribuição Fixa pelo prazo de vigência do contrato (ANAC, 2014, p. 14).

A primeira parcela foi paga ao final do $12^{\circ}$ mês contando da data da eficácia do contrato, e o pagamento das demais parcelas será realizado a cada 12 meses subseqüentes (ANAC, 2014). Embora esses valores estejam citados no contrato, há também cláusulas que expõem que o valor anual da contribuição fixa será reajustado pelo Índice Nacional de Preços ao Consumidor Amplo- IPCA todos os anos. A contribuição variável, também anual, corresponde a $5 \%$ da receita bruta da concessionária e de suas eventuais subsidiárias integrais. Dessarte, a concessionária deverá remunerar a União anualmente com a contribuição fixa, reajustada pelo IPCA, amortizando a outorga do leilão, e mais $5 \%$ de sua receita bruta daquele ano.

Grotti (2011) afirma que cobrar outorga pela concessão acarreta mais custos aos concessionários. Como a principal forma de remuneração da concessionária é por meio de pagamentos feitos pelos usuários, esses podem ser onerados de forma excessiva. Bandeira de Mello (2010) corrobora com a autora e afirma que essa situação é oposta à desejável, que seria a modicidade das tarifas.

Ressalta-se então, que o valor da outorga será pago à União pelos usuários do aeroporto, de quem a concessionária receberá esse valor e também seu lucro, principalmente por meio das receitas tarifárias. Bandeira de Mello (2010, p.717) critica o cerne dessa questão assinalando que "serviço público, por definição existe para satisfazer necessidades públicas e não para proporcionar ganhos ao Estado." E conclui que:

o serviço público desenganadamente não é instrumento de captação de recursos para o Poder Público. Este não é um capitalista a mais no sistema. Os recursos de que necessita para cumprir suas missões (inclusive a de prestar serviço público) são captáveis pela via tributária ou pela emissão de títulos (BANDEIRA DE MELLO, 2010, p.717) 
Acredita-se que o posicionamento do autor traga questionamentos ao modelo de concessão dos aeroportos, que foi idealizado e realizado como forma de captação de recursos pelo Estado.

Demonstra-se também a justificativa exposta pela Secretaria de Aviação Civil (2014) para a utilização do critério de maior valor de outorga no leilão, que é a origem do valor de contribuição fixa:

Em todo o mundo, os leilões de concessão de aeroportos são realizados com base na maior parcela de contribuição das receitas geradas pelos aeroportos. Isso se deve à necessidade de grandes e constantes investimentos no setor para a manutenção da qualidade dos serviços. No caso do Brasil, isso se reforça pela grande extensão do território e a existência de aeroportos que não são autossustentáveis. No modelo aeroportuário, um leilão por menor tarifa não garantiria redução no preço das passagens para o consumidor, nem recursos para os investimentos. Por outro lado, ao permitir maior investimento, o modelo proporciona também maior oferta de voos, o que possibilita mais alternativas e preços de passagens menores para os passageiros.

A justificativa da SAC/PR demonstra que os subsídios cruzados da Rede Infraero permanecerão com as concessões, juntamente com os problemas que acarreta. Nessa citação a SAC/PR (2014) afirma que o alto valor de outorga permitirá grandes investimentos no setor aéreo, contudo, questiona-se se esses investimentos não são de responsabilidade do poder público, devendo ser realizados com seus recursos.

As funções da concessionária são ampliar, manter e explorar, o aeroporto que arrematou, oferecendo serviços de qualidade, conforme disposto no contrato assinado por ambas as partes. Considerando o exposto por Bandeira de Mello (2010) não seria papel da concessionária financiar outros aeroportos que não sejam autossuficientes, ou o setor aéreo como um todo.

Todavia, a participação da Infraero, com $49 \%$ do capital social da concessionária traz mais uma dimensão à discussão sobre as obrigações financeiras da concessionária. A empresa pública sendo acionária da SPE que administra o Aeroporto de Confins, tem que participar também do pagamento da contribuição fixa anual e dos 5\% da receita bruta anual da concessionária. O dado obtido no balanço patrimonial da Infraero (2015b) é que em 2014 a empresa aportou $\mathrm{R} \$ 129.100 .000,00$ (cento e vinte e nove milhões e cem mil reais) para a constituição do capital da SPE de Confins. Comprova-se, desse modo, que a empresa participa tanto da governança, quanto das obrigações financeiras da concessionária, correspondentes à sua participação acionária.

Assim, a Infraero, empresa pública, que em 2014 recebeu R \$ 1.867.073.000,00 (um bilhão, oitocentos e sessenta e sete milhões e setenta e três mil reais) em aportes da União (INFRAERO, 2015B) deve remunerar à mesma União, mediante depósito no FNAC, valor proporcional à sua participação na concessionária.

Há, dessa forma, um processo complexo em que a União arrecada recursos provenientes da concessão de um lado, e despende recursos financiando a Infraero, uma das acionistas da concessionária, por outro lado.

\section{CONSIDERAÇÕES FINAIS}

Esse trabalho estudou o processo de transferência de gestão do Aeroporto de Confins para a iniciativa privada por meio da concessão iniciada em 2013. A concessão já era um regime de transferência da execução do serviço público para a iniciativa privada previsto na legislação brasileira, não sendo uma criação do governo que a implementou. 
Algumas particularidades da concessão do Aeroporto de Confins merecem destaque nessa abordagem final, principalmente por causarem controvérsias e questionamentos.

O processo de licitação escolhido para a concessão do Aeroporto de Confins foi o leilão, e teve como singularidade a inversão de fases. Geralmente os documentos de habilitação, que visam comprovar a regularidade jurídica, fiscal, habilitação técnica e econômico-financeira da proponente, são analisados e julgados em processo anterior à sessão pública do leilão. Quando há a inversão de fases, após a sessão pública do leilão, é que ocorre a análise dos documentos de habilitação, da proponente classificada em primeiro lugar. Essa prática pode permitir a existência de insuficiências na habilitação da proponente, em prol do alto valor de outorga por ela ofertado, e sua necessidade deveria ser melhor analisada nas próximas concessões de aeroportos.

O leilão seguiu o critério do maior valor de outorga para selecionar a concessionária. Segundo Bandeira de Mello (2010) a concessão não deveria ser uma forma de o Estado arrecadar divisas, e sim apenas visar a prestação do serviço público de qualidade. Ainda conforme o autor esse critério está em desarranjo com a real função do serviço público de satisfazer as necessidades públicas. A concessão passa a ser um meio de o Estado captar recursos, desviando sua função original (BANDEIRA DE MELLO, 2010).

Contudo, fato bastante peculiar, é que ainda que não tenha participado do leilão, a Infraero, como acionista da concessionária, tem que arcar com $49 \%$ do valor de outorga ofertado pelo grupo vencedor do leilão. Assim, ainda que o Estado esteja captando recursos com o serviço público, também está despendendo, visto que confere consideráveis aportes de capital à Infraero anualmente.

Conceder os aeroportos com alto valor de outorga foi justificado pela SAC/PR (2014), pois financiaria os grandes investimentos necessários no setor, bem como aeroportos que não se autossustentam. Todavia, ressalta-se que essa é a função do poder público e não do ente privado que está gerindo o aeroporto do qual ganhou a licitação. Haveria, seguindo esse critério, desvio de funções, tanto do Estado em lucrar com a transferência do serviço público, quanto da concessionária de arcar com despesas que ultrapassam a ampliação, manutenção e exploração do aeroporto. O modelo de concessão de aeroportos transforma a concessionária de responsável pela governança e investimentos no Aeroporto de Confins, para investidora no setor aeroportuário brasileiro como um todo. Cabe desse modo, evidenciar que esse não é um ponto pacífico e que merece ser discutido academicamente e também pela sociedade, maior impactada por essa escolha do poder público.

Um impacto dessa escolha para a sociedade está na modicidade de tarifas, um dos princípios previstos na Lei 8.987/95. Para manter o equilíbrio-econômico financeiro da concessionária, deve haver proporcionalidade entre suas despesas e receitas. Como o alto valor de outorga requer maiores gastos por parte da concessionária, essa terá que arrecadar mais. Sendo grande parte da arrecadação por meio das tarifas aeroportuárias, pagas direta ou indiretamente pelos usuários, há a possibilidade de onerar os passageiros do aeroporto. Além desse equilíbrio, o ente privado visa o próprio lucro, criando mais um fator que prejudica a modicidade das tarifas.

Algumas medidas foram tomadas pelo poder público para minimizar esse problema. Os tetos das tarifas foram fixados no contrato, bem como a fórmula de reajuste anual; e a concessionária tem a anuência do poder público para explorar outras atividades econômicas no complexo aeroportuário garantindo a arrecadação das receitas não tarifárias. Nota-se que houve preocupação do poder concedente em manter a modicidade das tarifas, contudo não se pode avaliar a eficiência dessas medidas, pela concessão estar em fase inicial.

Quanto à composição da BH- Airport, concessionária que gerencia o Aeroporto de Confins, estão presentes a SPE que detém $51 \%$ da participação acionária, constituída pela CCR e pela 
Zurich Airport, e a Infraero com 49\% do capital social. No caso da concessão dos aeroportos no Brasil o termo concessionária não é sinônimo de ente privado, já que apenas $51 \%$ da concessionária pertence ao setor privado. No modelo brasileiro a empresa que já administrava os aeroportos detém $49 \%$ da concessionária, permanecendo na gestão, mesmo após a concessão. A participação da Infraero como acionista da concessionária traz uma série de questionamentos ainda não esclarecidos pelo poder público.

Outro ponto controverso é que apesar de arrecadar divisas com o valor da outorga e a contribuição anual da concessionária, a União terá que arcar com $49 \%$ desses recursos, representando a Infraero, acionista da concessionária. Questiona-se assim, se esse modelo de concessão traz a captação de recursos concomitante ao desembolso dos mesmos pela União de forma incomum.

Conclui-se, dessarte, que o modelo de parceria entre o setor público e o privado para a gestão do Aeroporto de Confins é uma concessão não convencional, pois permite que a empresa pública que antes administrava o aeroporto se mantenha na administração do mesmo com uma quantia considerável de ações da concessionária. Esse híbrido entre o setor público e o ente privado foge aos padrões já existentes, distorcendo o modelo de concessão disposto pela legislação brasileira.

Esse trabalho traz um somatório de evidências, apresentando questionamentos sobre essa transferência inconforme. São abertas possibilidades para novos estudos inclusive exploratórios sobre esse modelo de concessão sui generis. Estudos para acompanhar como está sendo gerido o Aeroporto de Confins, conforme haja disponibilização dos dados, também devem ser realizados. Acredita-se que esses estudos poderão analisar a gestão da concessionária e apresentar comparações entre o que foi disposto no contrato e os processos gerenciais da concessão. 


\section{REFERÊNCIAS}

AGÊNCIA NACIONAL DE AVIAÇÃO CIVIL- ANAC. Sítio da Internet. Disponível em: <http://www.anac.gov.br> Acesso em: 03 nov. 2014.

Estudos de Viabilidade do Aeroporto Internacional Tancredo Neves- Confins: Relatórios. Brasília, DF. 2013b. Disponível em: <http://www2.anac.gov.br/Concessoes/galeao_confins/>. Acesso em: 5 dez. 2013.

BANDEIRA DE MELlO, Celso A. Curso de Direito Administrativo. $27^{\mathrm{a}}$ ed. São Paulo, Malheiros Editores, 2010.

BARDIN, Laurence. Análise de conteúdo. Lisboa: Edições 70, 1977.

BELÉM, Antônio Ronieel Bezerra. Leilão dos Aeroportos: uma análise da Restrição de Oferta Unitária. 2013. 56 f. Dissertação (Mestrado) - Curso de Mestrado em Economia, Departamento de Economia, Universidade de Brasília, Brasília, 2013. Disponível em: <http://repositorio.unb.br/bitstream/10482/14148/1/2013_AntonioRonieelBezerraBelem.pdf>. Acesso em: 12 dez. 2014.

BH AIRPORT. Sítio da internet. Disponível em: < http://www.bh-airport.com.br/> Acesso em: 10 set. 2014.

BM\&F BOVESPA. Sítio da internet. Disponível em: <http://www.bmfbovespa.com.br/ptbr/noticias/2013/ANAC-realiza-leilao-de-concessao-dos-Aeroportos-Internacionais-Galeao-eConfins-2013-11-22.aspx?tipoNoticia=1\&idioma=pt-br>. Acesso em: 08 jan. 2014

BNDES. Sítio da internet. Disponível em: <http://www.bndes.gov.br/SiteBNDES/bndes/bndes_pt/Areas_de_Atuacao/Infraestrutura/Log istica/condicoes_apoio_aeroportos_galeao_confins.html> Acesso em: 09 abr. 2015.

BRASIL. Constituição (1988). Constituição da República Federativa do Brasil. Brasília, DF: Senado Federal, 1988.

. Decreto $\mathrm{n}^{\mathrm{o}} 7.896$, de 1 de fevereiro de 2013. Dispõe sobre a inclusão no Programa Nacional de Desestatização - PND do Aeroporto Internacional do Rio de Janeiro/Galeão Antonio Carlos Jobim, localizado no Município do Rio de Janeiro, Estado do Rio de Janeiro, e do Aeroporto Internacional Tancredo Neves, localizado nos Municípios de Confins e de Lagoa Santa, Estado de Minas Gerais, e dá outras providências. Brasília, DF, 1 fev. 2103. Disponível em: <http://www.planalto.gov.br/ccivil_03/leis/L9491.htm\#art35>. Acesso em: 30 jan. 2014.

Lei $\mathrm{n}^{\circ} 7.565$ de 19 de dezembro de 1986. Dispõe sobre o Código Brasileiro de Aeronáutica. Brasília, DF, 19 dez. 1986. Disponível em: <http://www.planalto.gov.br/ccivil_03/leis/17565.htm> Acesso em: 19 maio 2014.

Lei $\mathrm{n}^{\circ} 8.987$ de 13 de fevereiro de 1995. Dispõe sobre o regime de concessão e permissão da prestação de serviços públicos previsto no art. 175 da Constituição Federal, e dá 
outras providências. Brasília, DF, 13 fev. 1995. Disponível em: <http://www.planalto.gov.br/ccivil_03/leis/18987cons.htm>. Acesso em: 7 dez. 2013.

Lei $\mathrm{n}^{\circ}$ 9.491, de 9 de setembro de 1997. Altera procedimentos relativos ao Programa Nacional de Desestatização, revoga a Lei $\mathrm{n}^{\circ}$ 8.031, de 12 de abril de 1990, e dá outras providências. Brasília, DF, 9 set. 1997. Disponível em: <http://www.planalto.gov.br/ccivil_03/leis/L9491.htm\#art35>. Acesso em: 30 jan. 2014.

Tribunal de Contas da União. Acórdão 3232/2011- Plenário. Relator: Ministro Aroldo Cedraz. Processo 032.786/2011-5. Ata 54/2011. Brasília, DF, 2011a. Sessão 07/12/2011. Disponível em: <https://contas.tcu.gov.br/egestao/documento_sisdoc/idSisdoc_3853687v19-83++ACORDAO--MIN-AC-2011-125.pdf?codArqCatalogado=3853687\&seAbrirDocNoBrowser=true > Acesso em: 21 out. 2014.

Tribunal de Contas da União. Acórdão 3233/2011- Plenário. Relator: Ministro Aroldo Cedraz. Processo: 032.696/2011-6. Ata 54/2011. Brasília, DF, 2011b. Sessão 07/12/2011.

Disponível em:

<https://contas.tcu.gov.br/egestao/documento_sisdoc/idSisdoc_3853691v19-30++ACORDAO--MIN-AC-2011-12-

5.pdf?codArqCatalogado=3853691\&seAbrirDocNoBrowser=true $>$ Acesso em: 21 out. 2014 .

Tribunal de Contas da União. Acórdão 3234/2011- Plenário. Relator: Ministro Aroldo Cedraz. Processo 032.695/2011-0. Ata 54/2011. Brasília, DF, 2011c. Sessão 07/12/2011.

<https://contas.tcu.gov.br/egestao/documento_sisdoc/idSisdoc_3853702v15-71++ACORDAO--MIN-AC-2011-12-

5.pdf?codArqCatalogado=3853702\&seAbrirDocNoBrowser=true > Acesso em: 21 out. 2014.

Tribunal de Contas da União. Acórdão 2466/2013 - Plenário. Relatora: Ministra Ana Arraes. Processo 007.578/2013-0. Ata 35/2013. Brasília, DF, 2013a. Sessão 11/09/2013. Disponível em: http://portal3.tcu.gov.br/portal/page/portal/TCU/imprensa/noticias/noticias_arquivos/007.5782013-0\%20(Concessao\%20de\%20Galeao\%20e\%20Confin> Acesso em: 18 out. 2014.

Tribunal de Contas da União. Acórdão 2666/2013 - Plenário. Relator: Ministro Augusto Sherman. Processo 007.578/2013-0. Ata 38/2013. Brasília, DF, 2013b. Sessão 02/10/2013.

Disponível em: $<$ https://contas.tcu.gov.br/egestao/ObterDocumentoSisdoc?codPapelTramitavel=50612264\&s eAbrirDocNoBrowser=true> Acesso em: 18 out. 2014.

Tribunal de Contas da União. Acórdão 2945/2014- Plenário. Relator: Ministro Marcos Bemquerer. Processo 007.578/2013-0. Ata 42/2014. Brasília, DF, 2014. Sessão 29/10/2014.

Disponível em: https://contas.tcu.gov.br/juris/Web/Juris/ConsultarTextual2/Jurisprudencia.faces?anoAcordao $=2014 \&$ colegiado $=$ PLENARIO\&textoPesquisa $=+2014 \&$ numeroAcordao $=2905 \&>$ Acesso em: 27 jan. 2015.

CÂMARA, Jacintho Arruda. A experiência brasileira nas concessões de serviços públicos. 
In: SUNDFELD, Carlos Ari (Org.). Parcerias público-privadas. São Paulo: Malheiros, 2011. p. 157-179.

CAMPOS NETO, Carlos A. da S.; SOUZA, Frederico H. de. Aeroportos no Brasil: investimentos recentes, perspectivas e preocupações. Nota técnica n.5 Ipea. Brasília, abr. 2011. Disponível em: <http://www.ipea.gov.br/portal/images/stories/PDFs/110414_nt005_diset.pdf> Acesso em: 04 jan. 2014.

DI PIETRO, Maria Sylvia Z. Direito Administrativo. 24 ed. São Paulo: Atlas, 2011.

EMPRESA BRASILEIRA DE INFRAESTRUTURA AEROPORTUÁRIA- INFRAERO. Sítio da Internet. Disponível em: <http://www.infraero.gov.br>. Acesso em: nov. 2013 à abr. 2015.

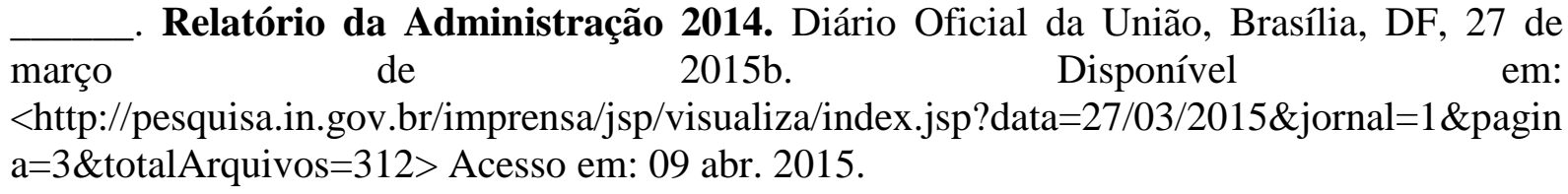

ESPÍRITO SANTO JR, Respicio Antônio do; PRAZERES, Dorieldo Luiz dos; SANTANA, Érico Soriano Martins. Gerenciamento Privado de Aeroportos: Fatores Positivos e Negativos do Caso Brasileiro. Rio de Janeiro: Instituto Cepta, 2010.

GROTTI, Dinorá Adelaide Musetti. A experiência brasileira nas concessões de serviços públicos. In: Carlos Ari Sundfeld (Org.). Parcerias público-privadas. São Paulo: Malheiros, 2011. p. 180-251.

GRUPO CCR. Sítio da internet. Disponível em: <http://www.grupoccr.com.br>. Acesso em: 14 out. 2014.

INSTITUTO DE PESQUISA ECONÔMICA APLICADA - IPEA. Comunicados do IPEA: Panorama e perspectivas para o transporte aéreo no Brasil e no mundo. Série Eixos do Desenvolvimento Brasileiro, n. 54. Brasília, 2010.

JUSTEN FILHO, Marçal. Curso de Direito Administrativo. 7. ed. rev. e atual. 1 reimp. Belo Horizonte: Fórum, 2011.

MARTINS, Daniel M.; TESSEROLLI, Eduardo R. C. Notas Sobre a Infraestrutura Aeroportuária Estatal no Brasil: Passado, Presente e Futuro e sua Relação com o Regime Diferenciado de Contratações. In: DEMETERCO NETO, Antenor; CASTRO, Rodrigo P. A. (Coord.). Temas de direito econômico: A copa do mundo de 2014 e Os jogos olímpicos de 2016. Curitiba: Clássica, 2013. Cap. 6. p. 123-150. Disponível em: <http://www.editoraclassica.com.br/novo/ebooksconteudo/Tema-de-direito-Copa-2014.pdf>. Acesso em: 17 maio 2014

MCKINSEY \& COMPANY. Estudo do Setor de Transporte Aéreo do Brasil: 
Relatório Consolidado. Rio de Janeiro: McKinsey \& Company, 2010. Disponível em: <http://www.bndes.gov.br/SiteBNDES/export/sites/default/bndes_pt/Galerias/Arquivos/empr esa/pesquisa/chamada3/relatorio_consolidado.pdf>. Acesso em: 15 mar. 2014.

SECRETARIA DE AVIAÇÃO CIVIL DA PRESIDÊNCIA DA REPÚBLICA. Sítio da internet. Disponível em: <http://www.aviacaocivil.gov.br/banco-de-informacoes >. Acesso em 06 jan. 2014.

Portaria $\mathrm{n}^{\circ} 183$ de 14 de agosto de 2014. Revoga a Portaria SAC-PR n 110, de 8 de julho de 2013, e aprova o Plano Geral de Outorgas para a exploração de aeródromos civis públicos. Brasília, 15 ago. 2014. Disponível em: <http://www.aviacaocivil.gov.br/acesso-ainformacao/outorgas/portaria-no-183-de-14-ago-2014-aprova-o-plano-geral-de-outorgaspgo.pdf> Acesso em: 15 set. 2014.

PRAZERES, Dorieldo L. dos. A Exploração de Aeroportos em Regime Privado: (Regime de Autorização). 2011. 79 f. Monografia (Especialização) - Curso de Gestão de Aviação Civil, Departamento de Centro de Estudos em Transporte, Universidade de Brasília, Brasília, 2011. Disponível

em: <https://www.academia.edu/5471100/A_Exploracao_de_Aeroportos_em_Regime_Privado_R egime_de_Autorizacao_>. Acesso em: 15 set. 2014. 